\title{
Hybrid Intelligent Approach for Predicting Product Compositions of a Distillation Column
}

\author{
Yousif Al-Dunainawi \\ Electronic and Computer Engineering Department \\ College of Engineering, Design and Physical Sciences \\ Brunel University London \\ Uxbridge, London, UK
}

\author{
Maysam F. Abbod \\ Electronic and Computer Engineering Department \\ College of Engineering, Design and Physical Sciences \\ Brunel University London \\ Uxbridge, London, UK
}

\begin{abstract}
Compositions measurement is a vitally critical issue for the modelling and control of distillation process. The product compositions of distillation columns are traditionally measured using indirect techniques via inferring tray compositions from its temperature or by using an online analyser. These techniques were reported as inefficient and relatively slow methods. In this paper, an alternative procedure is presented to predict the compositions of a binary distillation column. Particle swarm optimisation based artificial neural network PSO-ANN is trained by different algorithms and tested by new unseen data to check the generality of the proposed method. Particle swarm optimisation is utilised, here, to choose the optimal topology of the network. The simulation results have indicated a reasonable accuracy of prediction with a minimal error between the predicted and simulated data of the column.
\end{abstract}

Keywords-Hybrid Intelligence; Prediction; Distillation Column; Neural network; Particle swarm optimisation

\section{INTRODUCTION}

Over the past few decades, great developments in online analysis, monitoring and measurement of dynamic processes were made in various applications [1]-[5]. This development is partially motivated by the desire to improve quality. Unambiguously, quality is a significant indication that has a substantial impact on productivity and economy of manufacture, particularly in the field of mass production [2]. Direct measurement of the product compositions of the distillation column is a crucial issue. However, its disadvantages at stream process lie in difficulty, unreliability and high capital and operational cost. These disadvantages will have an exponentially negative effect when more than one analysis are needed to obtain a clearer picture of the different streams involved. Consequently, indirect and inferential measurement techniques are being used to design and run many distillation columns. These columns operate widely in chemical and petrochemical plants as well as refineries to separate mixtures into their individual components.

Not only non-linearity and transit behaviour make distillation, as a process, complicated to control, but the product compositions also cannot be promptly measured, nor reliable. The delay caused by the measurement and analysis of compositions will negatively affect the effectiveness and robustness of control [6]. An indirect method is proposed to monitor the products compositions of the column by using tray temperature inside the column, albeit this feature is an unreliable indicator of product compositions [7], [8]. Moreover, other considerations like consistent maintenance, regular calibrations, and high-cost equipment make composition analysers an ineffective solution for precise online measurements. Consequently, soft sensing or inferential systems have been proposed recently as practical options to replace hardware measurement systems [9].

Artificial neural networks (ANNs) is one of the most attention-grabbing branches of artificial intelligence, which has grown rapidly in the recent years as an optimal solution for the modelling, and prediction of dynamic systems. ANNs have shown outstanding performance to learn the inputoutput relationship of nonlinear and complex systems. This relationship could be easily, quickly and efficiently found out via reducing the error between the network output(s) and the actual output(s). After the network is trained, the output can be predicted within few seconds. ANN-based models are still being applied successfully to overcome engineering problems in different fields such as adaptive control, pattern recognition, robotics, image processing, medical diagnostics, fault detection, process monitoring, renewable and sustainable energy, laser applications and nonlinear system identification [10]-[17].

The most crucial task which faces the neural network constructer is the proper selection of the network topology to solve a particular problem. The topology means, here, the number of nodes (neurones) and the number of layers in the hidden zone. Therefore, one of the most efficient methods to determine the optimal network structure is evolutionary algorithm EA methods such as genetic algorithm GA [18] and practical swarm optimisation PSO [19] and so on.

This paper proposed a PSO-based neural network as a predictor model for estimating the product compositions of a binary distillation column.

\section{Distillation Column Modelling AND DESCRIPTION}

Distillation is, undoubtedly, one of the most important processes in chemical and petrochemical plants. Distillation columns are used as separators of chemical compounds in petroleum, natural gas, liquid and chemical industries [20]. The major disadvantage of using those columns is that they are considered as an intensive energy process. A report from the US Department of Energy has indicated that distillation is the 
largest consumer of energy in the chemical industry; typically, it accounts $40 \%$ of the energy consumed by petrochemical plants. Despite its "thirst" for energy, distillation persists to be a widely utilised method for separations [21], [22].

Figure 1 is a schematic diagram of a binary distillation column, in which a feed mixture is separated into a distillate product (overhead) and a bottom product. Also, heat is transferred into the column via a reboiler (heat exchanger) to vaporise some of the liquid from the base of the column. The vapour travels up through trays inside the column to reach the top and, then, comes out to be liquefied in a condenser. Liquid from the condenser, at that point, drops into the reflux drum. Finally, the distillate is removed from this drum as a pure product. additionally, some liquid (reflux) is fed back near the top of the column while the impure product is produced at the bottom outlet.

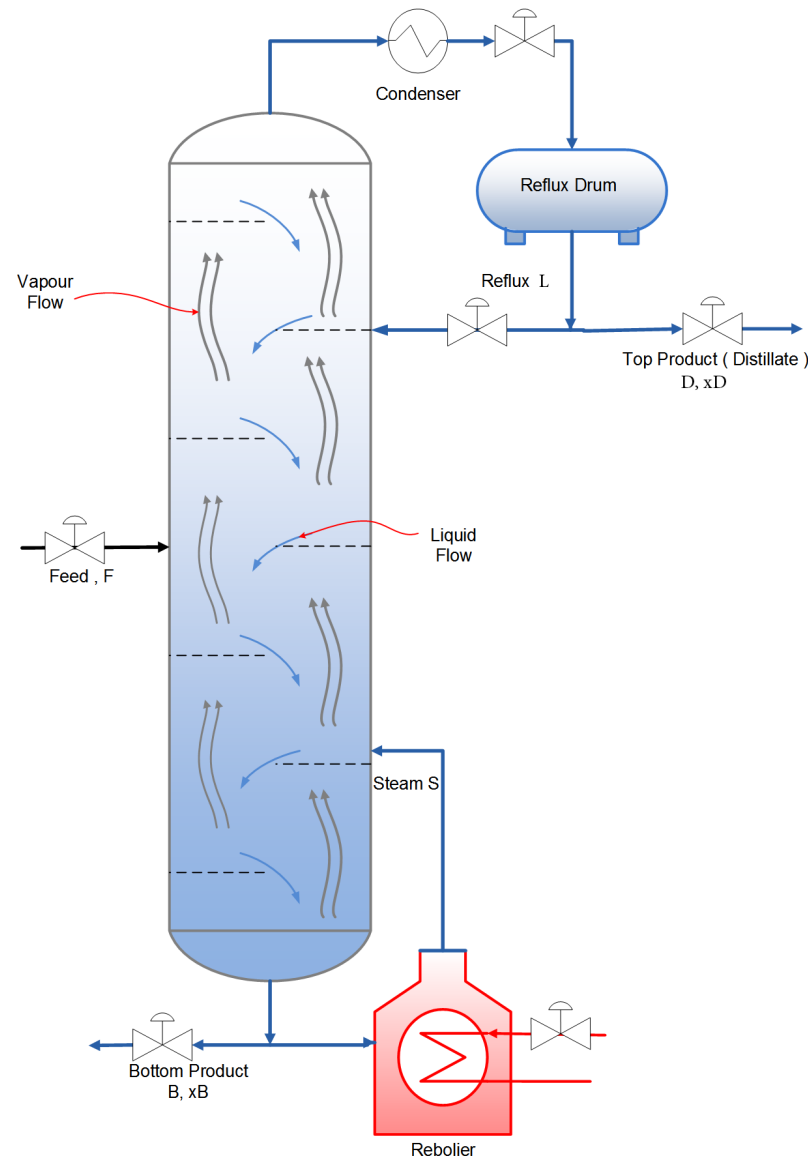

Fig. 1: Schematic diagram of a binary distillation column

The dynamic model can be simplified under the following assumptions:

- No chemical reactions occur in all stages of the column

- Constant pressure (open to atmosphere pressure)

- $\quad$ Binary mixture

- Constant relative volatility
- No vapour hold-up occurs

- Perfect mixing and equilibrium for vapour-liquid on all stages

While the operating conditions and technical aspects of the distillation column are detailed in the appendix at the end of this paper.

Accordingly, the mathematical expression of the model can be represented with the assumptions by the following equations: On each tray (excluding reboiler, feed and condenser stages):

- On each tray (excluding reboiler, feed and condenser stages):

$$
M_{i} \frac{d x_{i}}{t}=L_{i+1} x_{i+1}+V_{i-1} y_{i-1}-L_{i} x_{i}-V_{i} y_{i}
$$

- $\quad$ Above the feed stage $i=N F+1$ :

$M_{i} \frac{d x_{i}}{t}=L_{i+1} x_{i+1}+V_{i-1} y_{i-1}-L_{i} x_{i}-V_{i} y_{i}+F_{V} y_{F}$

- $\quad$ Below the feed stage $i=N F$ :

$M_{i} \frac{d x_{i}}{t}=L_{i+1} x_{i+1}+V_{i-1} y_{i-1}-L_{i} x_{i}-V_{i} y_{i}+F_{L} X_{F}$

- $\quad$ In the reboiler and column base $i=1, x_{i}=x B$ :

$$
M_{B} \frac{d x_{i}}{t}=L_{i+1} x_{i+1}-V_{i} y_{i}+B x_{B}
$$

- In the condenser, $i=N+1, x D=x N+1$ :

$$
M_{D} \frac{d x_{i}}{t}=V_{i-1} y_{i-1}-L_{i} x_{D}-D x_{D}
$$

- Vapour-liquid equilibrium relationship for each tray [23]:

$$
y_{i}=\frac{\alpha x_{i}}{1+(\alpha-1) x_{i}}
$$

- The flow rate at constant molar flow:

$$
L_{i}=L, V i=V+F_{V}
$$

since

$$
\begin{aligned}
& F_{L}=q_{F} \times F \\
& F_{v}=F+F_{L}
\end{aligned}
$$

- The flowrate of both condenser and reboiler as: Reboiler:

$$
B=L+F_{L}-V
$$

Condenser:

$$
D=V+F_{V}-L
$$

- $\quad$ The feed compositions $x F$ and $y F$ are found from the flash equation as:

$$
F_{z F}=F_{L} \times x_{F}-F_{V} \times y_{F}
$$




\section{HYBRID MODEL DEVELOPMENT AND OPTIMISATION}

Recently, hybridization or combination of different learning and adaptation techniques has been employed to a large number of new intelligent system designs. The main aim of integrating these techniques is to overcome individual limitations and to achieve synergetic effects [24].

Therefore, a PSO-based artificial neural network is proposed as an estimator tool of a binary distillation column.

\section{A. Artificial Neural Networks}

Artificial neural network (ANNs) is a complicated system, which is composed of numerous neural nets. These nets fundamentally based on the principal understanding of the function, structure, and the mechanism of the brain of humankind [25]. In the last two decades or so, ANNs have been applied to a widespread range of applications due to their ability to analyse and capture the complexity and nonlinearity features of dynamic processes. One of the major applications of ANNs is a modelling or identification process of complex systems [26].

It is worth mentioning that the topology of the network is a crucial matter where as choosing the number of the neurones and layers in the hidden zone is not an easy task. So far, no systematic approach or automatic methods have been used to tackle this issue. Because the network structure depends on the nature and features of the process that would be modelled. Therefore, there are, probably, only two research methods to select from, a blind or heuristic. The blind approach, or trial and error, is an unguided and arbitrary search method, to which all possible alternatives are applied to find the optimal solution. Although this technique can eventually find the optimal ANN topology with limited search space, this method is not practical because it is considered highly expensive in terms of time and computations.

\section{B. Particle Swarm Optimisation}

Ever since particle swarm optimisation (PSO) has been proposed by Kennedy and Eberhart in 1995 [27] and 2001 [28], PSO algorithm turned to be vastly successful. The several of researchers have presented the merit of the implementation of PSO as an optimiser for various applications [29]. In PSO procedure, all individuals or particles (commonly between 10 and 100) are located at a random position and are supposed to move randomly in a defined direction in the search space. Each particle direction is then changed steadily to move assuredly along the direction of its best previous positions to discover even a new better position according to certain criteria or an objective function (fitness). The initial particle velocity and position are selected arbitrarily, and the following velocity equation can update them as

$$
V c_{i+1}=w V_{i}+C 1 R 1 \times\left(P b_{i}-x_{i}\right)+C 2 R 2 \times\left(G b-x_{i}\right)
$$

Whereas the new particle is calculated by adding the previous one to the new velocity as shown in the following equation:

$$
x_{i+1}=x_{i}+V c_{i+1}
$$

where: $V c$ : velocity of the particle, $X$ : position of the particle, $R 1, R 2$ : independent random variables uniformly distributed in
$[0,1], C 1, C 2$ : acceleration coefficients as well as $w$ : inertia weight. Eq. 13 is used to compute the new velocity of the particle according to its preceding velocity and the distances of its current position from its own best position $(\mathrm{Pb})$ and the global best position $(G B)$. Then, the particle moves to a new place in the search space, according to Eq. 14. The performance of each particle is measured according to a predefined objective function (performance index).

\section{Hybrid System Design}

Evolutionary-based optimisation, like PSO, can be applied by only simple mathematical operations with a few lines of code [30]. This feature provides a low-cost method concerning both memory and speed requirements. Thus, in this study, PSO is chosen to find the optimal network topology of the prediction model as depicted in Figure 2.

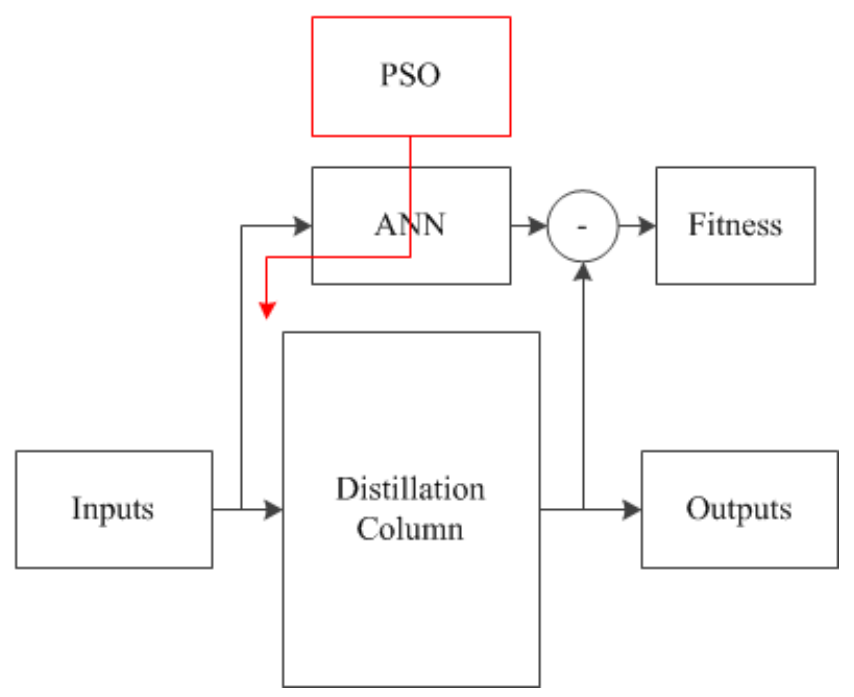

Fig. 2: Schematic diagram of the proposed hybrid system

\section{Simulation And Results}

In this study, the reflux (L) and the boil-up (V) flow rates had been used as inputs to the network while distillate and bottom composition chosen as outputs. The dataset implemented for the training, validation and testing of ANN was generated by applying 40 distributed random values, each lasting 50 sampling time for (L) and (V) as shown in Figure 3. The distillate composition was approximately between 0.95 and 1 (mole fraction), while the bottom composition was around 0.005 to 0.12 (mole fraction) and a total of 2000 datasets were collected for identification, Figure 4 presents the simulated data of the column.

The dataset obtained by the simulation was randomly divided into $70 \%, 15 \%$ and $15 \%$ for training, validation and testing respectively. Feedforward multilayer network had been implemented to predict the product compositions of the distillation column. In addition, various backpropagation training algorithms, namely; Gradient Descent (GD), Scaled Conjugate Gradient (SCG) and LevenbergMarquardt (LM) were separately applied to decide which one performs better 


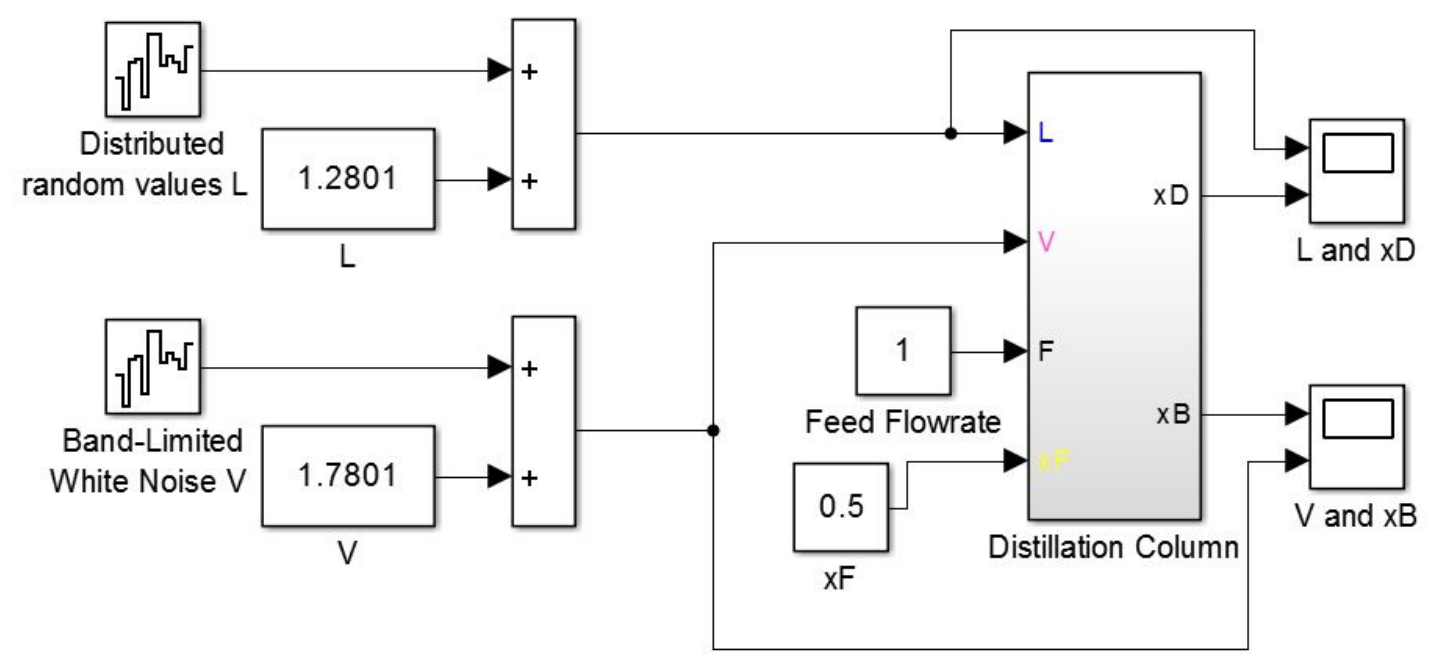

Fig. 3: MATLAB/Simulink model of the distillation column

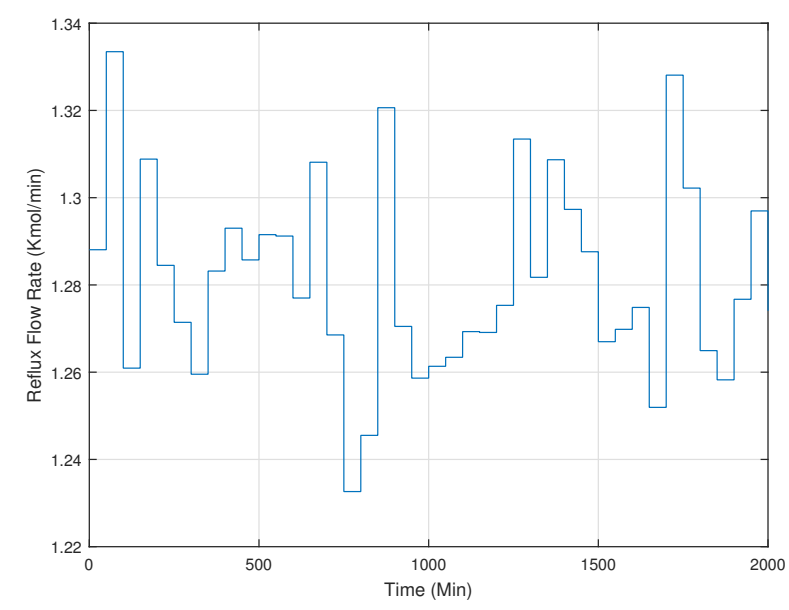

(a) Reflux folw rate

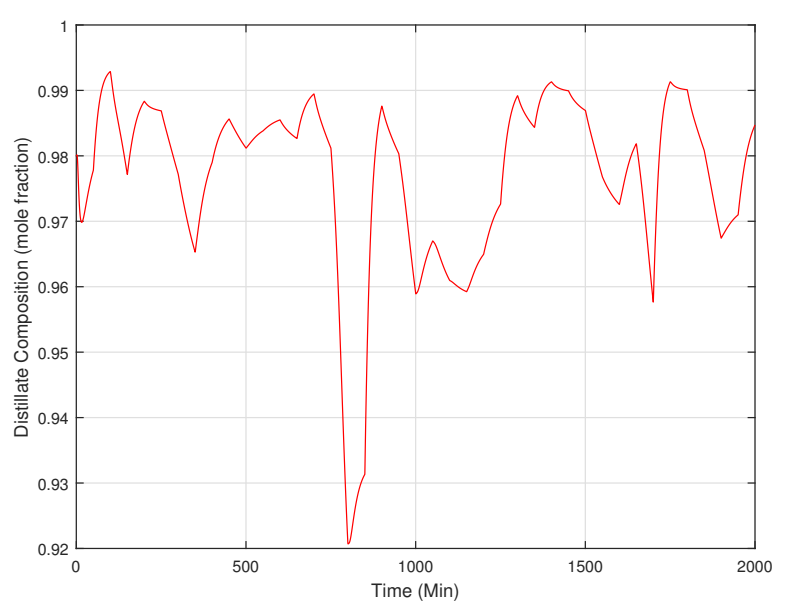

(b) Distillate composition

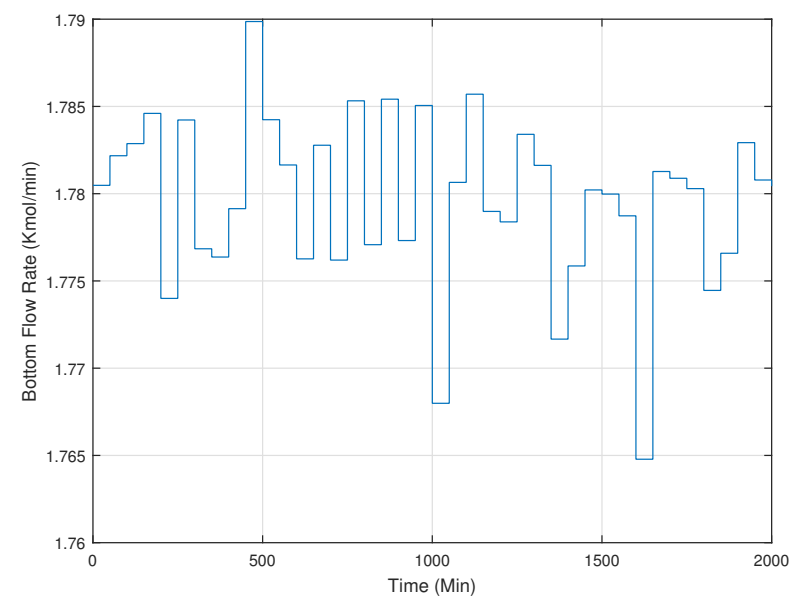

(c) Boil-up flow rate

than the others. Moreover, Log-sigmoid activation function was embedded in the neurones of the hidden layer(s) because of its differentiability. PSO was employed to find the optimal structure of the network, the best operational parameters of PSO algorithm were chosen after extensive simulations and were set as following: For each of the network architecture,

$\begin{array}{lc}\text { No. of variables (dimensions) } & 2 \\ \text { Size of the swarm (no. of particles) } & 50 \\ \text { Maximum iterations (max) } & 100 \\ \text { Cognitive acceleration }(C 1) & 1.2 \\ \text { Social acceleration }(C 2) & 0.12 \\ \text { Momentum or inertia }(w) & 0.9 \\ \text { Minimum search space } & 1 \\ \text { Maximum search space } & 25\end{array}$

the training algorithms had been run ten times with different random initial weights and biases. After investigating the performance of different architectures using the PSO technique, a network with two hidden layers (including 23 neurons in the first and 25 in the second) trained by LM algorithm have 


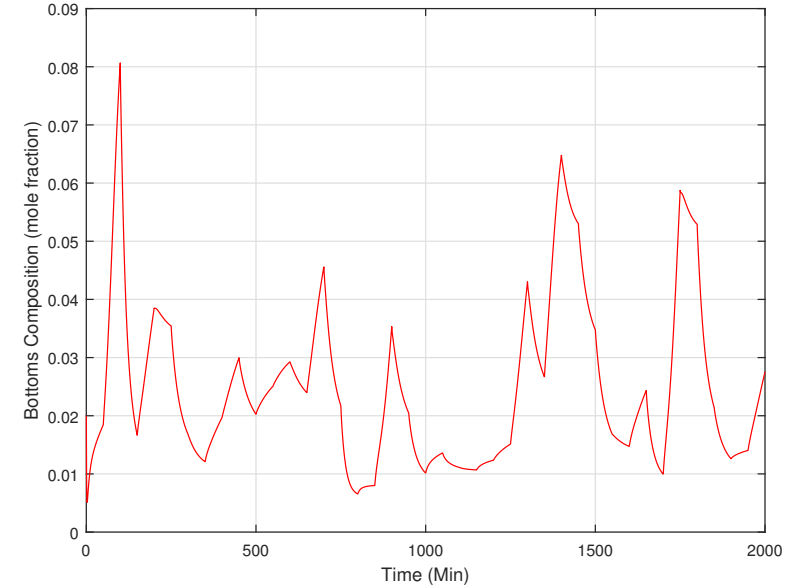

(d) Bottoms composition

Fig. 4: Inputs/outputs of the simulation of the distillation column

indicated reasonably good results. Figures 5 and 6 show the performance of the network as a mean square error (MSE) versus the network architecture of the single and double hidden layer respectively. Table I demonstrates the training, testing and validation performances of different training approaches of both one and two layers in the hidden zone.

It is clearly indicated that much better results are found using LM as training algorithm with two hidden layers topology because LM uses Hessian matrix approximation as a secondorder method to calculate the change in gradient. Figures 7 and 8 display regression plots of the network outputs on both compositions of training and test sets. For a perfect fit, the data must fall along a 45-degree line, where the network outputs are equal to the targets. The network with two hidden layers trained by LM algorithm, the fit, is reasonably good of both datasets, with $\mathrm{R}$ values in each case of 0.99 or above. Checking the test set is importantly required for examining the generalisation of the network of unseen data in the learning stage. It is worth noting that the network training and simulation was performed using MATLAB ${ }^{\mathrm{R}}$ and Simulink ${ }^{\mathrm{R}}$ platform.

\begin{tabular}{|c|c|c|c|c|c|c|}
\hline $\begin{array}{l}\text { Training } \\
\text { Method }\end{array}$ & $\begin{array}{l}\text { No. of } \\
\text { Hidden } \\
\text { Layers }\end{array}$ & $\begin{array}{l}\text { No. of } \\
\text { Neurones }\end{array}$ & $\begin{array}{l}\text { Training } \\
\text { MSE }\end{array}$ & $\begin{array}{l}\text { Testing } \\
\text { MSE }\end{array}$ & $\begin{array}{l}\text { Validatio } \\
\text { MSE }\end{array}$ & $\begin{array}{l}\text { Time } \\
\text { (sec) }\end{array}$ \\
\hline \multirow[t]{2}{*}{$G D$} & 1 & 4 & $\begin{array}{l}3.972 \times \\
10^{-4}\end{array}$ & $\begin{array}{l}3.952 \times \\
10^{-4}\end{array}$ & $\begin{array}{l}3.996 \times \\
10^{-4}\end{array}$ & 12.40 \\
\hline & 2 & $9-2$ & $\begin{array}{l}2.047 \times \\
10^{-4}\end{array}$ & $\begin{array}{l}2.112 \times \\
10^{-4}\end{array}$ & $\begin{array}{l}2.015 \times \\
10^{-4}\end{array}$ & 11.84 \\
\hline \multirow[t]{2}{*}{$S C G$} & 1 & 19 & $\begin{array}{l}1.529 \times \\
10^{-5}\end{array}$ & $1.60^{-5} \times$ & $1.50^{-5} \times$ & 12.39 \\
\hline & 2 & $20-25$ & $\begin{array}{l}9.392 \times \\
10^{-7}\end{array}$ & $\begin{array}{l}9.429 \times \\
10^{-7}\end{array}$ & $\begin{array}{l}9.743 \times \\
10^{-7}\end{array}$ & 38.39 \\
\hline \multirow[t]{2}{*}{$L M$} & 1 & 25 & $\begin{array}{l}1.12 \times \\
10^{-6}\end{array}$ & $\begin{array}{l}1.225 \times \\
10^{-6}\end{array}$ & $\begin{array}{l}1.195 \times \\
10^{-6}\end{array}$ & 18.58 \\
\hline & 2 & $23-25$ & $\begin{array}{l}4.365 \times \\
10^{-9}\end{array}$ & $\begin{array}{l}3.984 \times \\
10^{-9}\end{array}$ & $\begin{array}{l}7.8 \\
10^{-9}\end{array} \times$ & 11.37 \\
\hline
\end{tabular}

TABLE I: Performances (MSE) of different PSO-ANN topologies
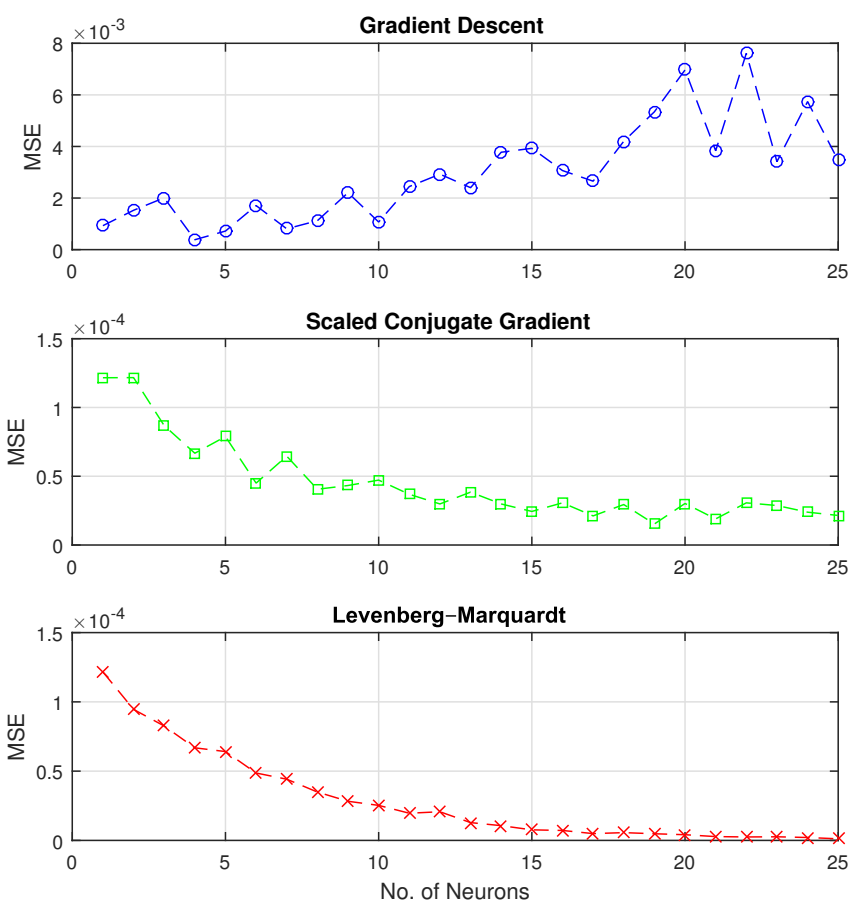

Fig. 5: Performance curves of one hidden layer PSO-ANN of different algorithms
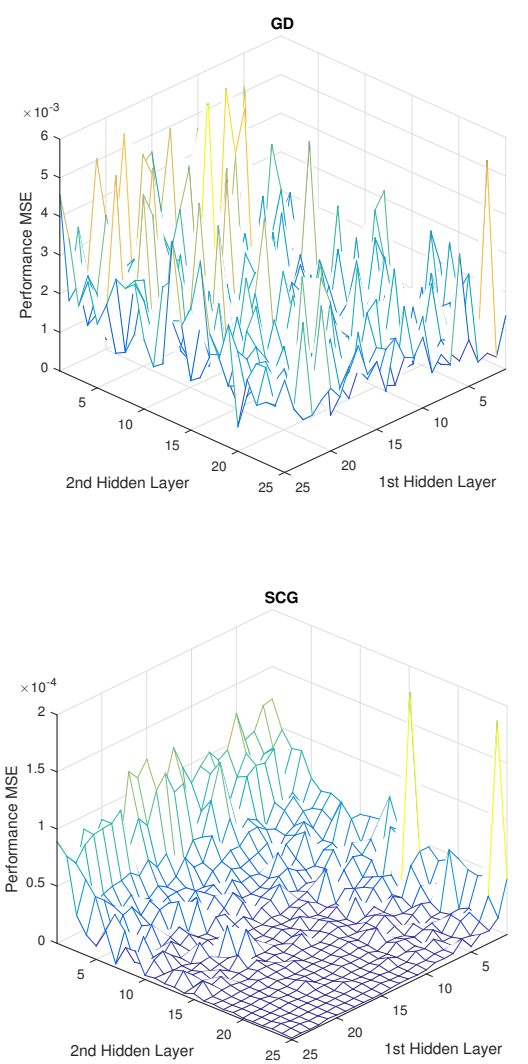
LM

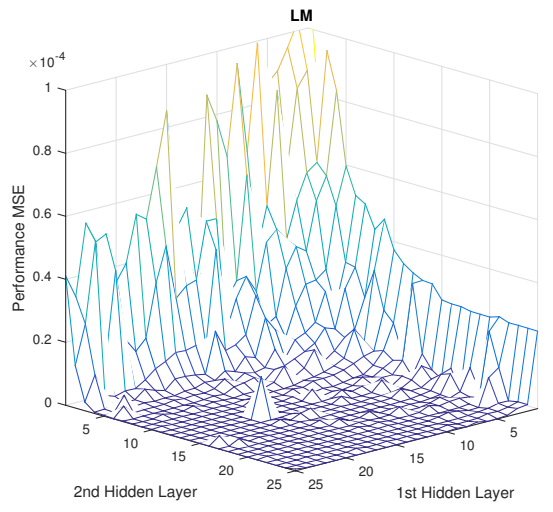

Fig. 6: Performance 3D surfaces of two hidden layers PSOANN of different algorithms

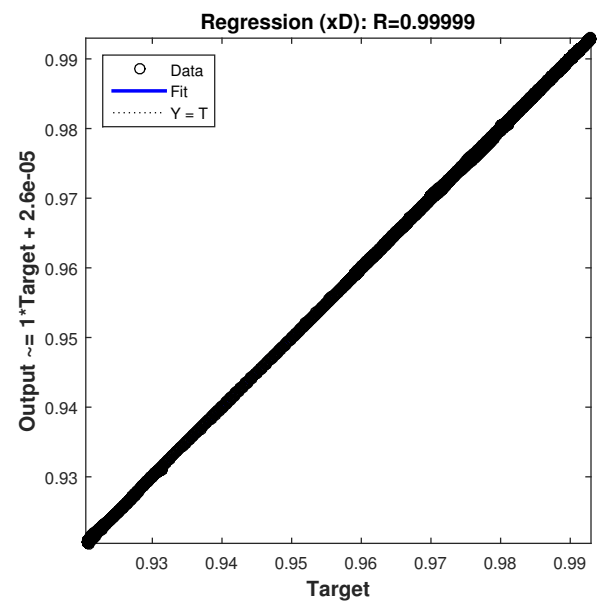

(a) Distillate composition prediction

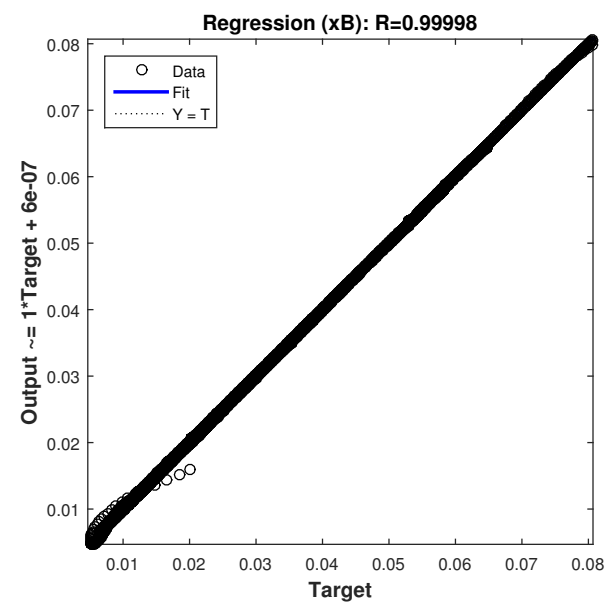

(b) Bottoms composition prediction

Fig. 7: The regression line between predicted and simulated compositions of training set

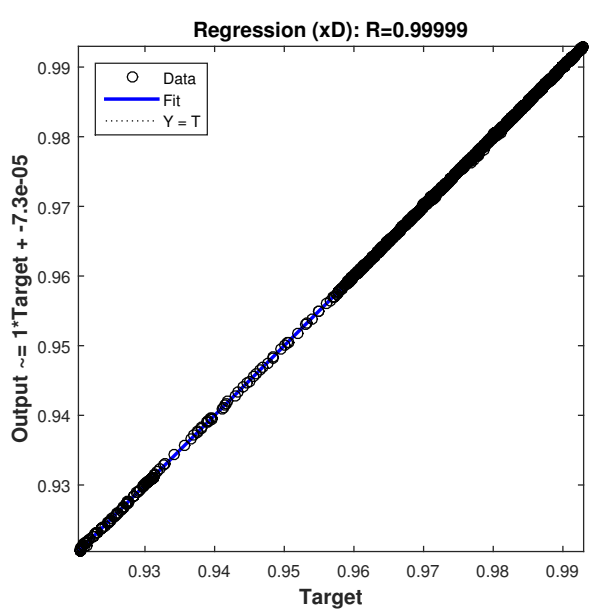

(a) Distillate composition prediction

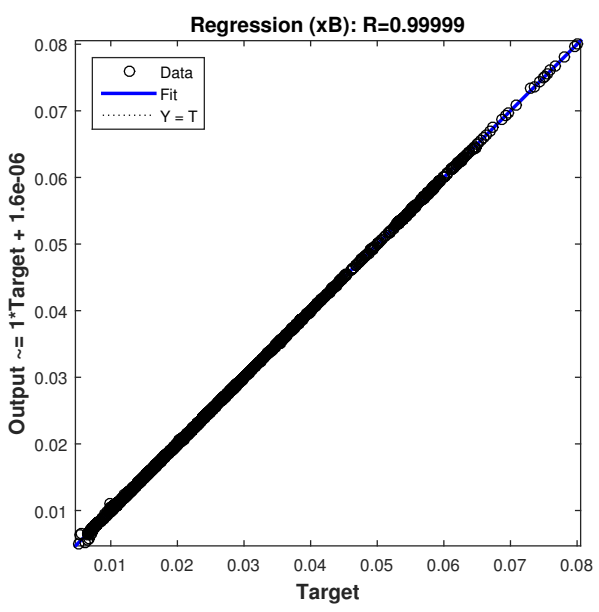

(b) Bottoms composition prediction

Fig. 8: The regression line between predicted and simulated compositions of testing set

\section{Conclusion}

A PSO-based artificial neural network has been proposed as an intelligent prediction approach to estimate product compositions of a binary distillation column; boil-up and reflux were used as inputs to the network. A double layer in the hidden zone with 23-25 neurones architecture was presented the optimal performance of the prediction model after examining different training algorithms and topologies using particle swarm optimisation. the network trained by LevenbergMarquardt algorithm gave more accurate results with less MSE compared to Gradient Descent and Scaled Conjugate Gradient. Therefore, the precision of predicted compositions of the distillation column using LM algorithm has shown to be high, and the estimated compositions have approximately been in agreement with the simulation results. The proposed ANN could be used efficiently to improve the performance of the different neural network controllers like NARMA-L2, direct inverses and NN predictive controller, which mainly depend 
on the prediction performance, which is to be the subject of future work.

\section{ACKNOWLEDGMENT}

The corresponding author is grateful to the Iraqi Ministry of Higher Education and Scientific Research for supporting the current research.

\section{REFERENCES}

[1] R. Teti, K. Jemielniak, G. ODonnell, and D. Dornfeld, "Advanced monitoring of machining operations," CIRP Annals-Manufacturing Technology, vol. 59, no. 2, pp. 717-739, 2010.

[2] R. X. Gao, X. Tang, G. Gordon, and D. O. Kazmer, "Online product quality monitoring through in-process measurement," CIRP AnnalsManufacturing Technology, vol. 63, no. 1, pp. 493-496, 2014.

[3] A. Vijayakumari, A. Devarajan, and N. Devarajan, "Decoupled control of grid connected inverter with dynamic online grid impedance measurements for micro grid applications," International Journal of Electrical Power \& Energy Systems, vol. 68, pp. 1-14, 2015.

[4] H. Wang, P. Senior, R. Mann, and W. Yang, "Online measurement and control of solids moisture in fluidised bed dryers," Chemical Engineering Science, vol. 64, no. 12, pp. 2893-2902, 2009.

[5] A. K. Pani and H. K. Mohanta, "Online monitoring and control of particle size in the grinding process using least square support vector regression and resilient back propagation neural network," ISA transactions, vol. 56, pp. 206-221, 2015.

[6] A. M. F. Fileti, L. S. Pedrosa, and J. A. Pereira, "A self tuning controller for multicomponent batch distillation with soft sensor inference based on a neural network," Computers \& Chemical Engineering, vol. 23, pp. S261-S264, 1999.

[7] W. Luyben, "Feedback control of distillation columns by double differential temperature control," Industrial \& Engineering Chemistry Fundamentals, vol. 8, no. 4, pp. 739-744, 1969.

[8] T. Mejdell and S. Skogestad, "Estimation of distillation compositions from multiple temperature measurements using partial-least-squares regression," Industrial \& Engineering Chemistry Research, vol. 30, no. 12, pp. 2543-2555, 1991.

[9] L. Fortuna, S. Graziani, and M. G. Xibilia, "Soft sensors for product quality monitoring in debutanizer distillation columns," Control Engineering Practice, vol. 13, no. 4, pp. 499-508, 2005.

[10] M. A. Hussain, "Review of the applications of neural networks in chemical process controlsimulation and online implementation," Artificial intelligence in engineering, vol. 13, no. 1, pp. 55-68, 1999.

[11] N. D. Ramirez-Beltran and H. Jackson, "Application of neural networks to chemical process control," Computers \& industrial engineering, vol. 37, no. 1, pp. 387-390, 1999.

[12] P. J. Drew and J. R. Monson, “Artificial neural networks,” Surgery, vol. 127, no. 1, pp. 3-11, 2000.

[13] J. W. Catto, D. A. Linkens, M. F. Abbod, M. Chen, J. L. Burton, K. M. Feeley, and F. C. Hamdy, "Artificial intelligence in predicting bladder cancer outcome a comparison of neuro-fuzzy modeling and artificial neural networks," Clinical Cancer Research, vol. 9, no. 11, pp. 4172 4177, 2003.

[14] A. Khosravi, S. Nahavandi, D. Creighton, and A. F. Atiya, "Comprehensive review of neural network-based prediction intervals and new advances," Neural Networks, IEEE Transactions on, vol. 22, no. 9, pp. 1341-1356, 2011.

[15] F. Amato, A. López, E. M. Peña-Méndez, P. Vaňhara, A. Hampl, and J. Havel, "Artificial neural networks in medical diagnosis," Journal of applied biomedicine, vol. 11, no. 2, pp. 47-58, 2013.

[16] S. Mondal, A. Bandyopadhyay, and P. K. Pal, "Application of artificial neural network for the prediction of laser cladding process characteristics at taguchi-based optimized condition," The International Journal of Advanced Manufacturing Technology, vol. 70, no. 9-12, pp. 2151-2158, 2014.
[17] M. Maarouf, A. Sosa, B. Galván, D. Greiner, G. Winter, M. Mendez, and R. Aguasca, "The role of artificial neural networks in evolutionary optimisation: A review," in Advances in Evolutionary and Deterministic Methods for Design, Optimization and Control in Engineering and Sciences. Springer, 2015, pp. 59-76.

[18] L. M. Lima de Campos, L. de Oliveira, and R. Celio, "A comparative analysis of methodologies for automatic design of artificial neural networks from the beginnings until today," in Computational Intelligence and 11th Brazilian Congress on Computational Intelligence (BRICSCCI \& CBIC), 2013 BRICS Congress on. IEEE, 2013, pp. 453-458.

[19] R. K. Agrawal and N. G. Bawane, "Multiobjective pso based adaption of neural network topology for pixel classification in satellite imagery," Applied Soft Computing, vol. 28, pp. 217-225, 2015.

[20] M. L. Darby and M. Nikolaou, "Identification test design for multivariable model-based control: an industrial perspective," Control Engineering Practice, vol. 22, pp. 165-180, 2014.

[21] R. W. Baker, Membrane separation systems: recent developments and future directions. Noyes Publications, 1991.

[22] C. L. Smith, Distillation control: An engineering perspective. John Wiley \& Sons, 2012.

[23] W. L. Luyben, Distillation design and control using Aspen simulation. John Wiley \& Sons, 2013.

[24] A. Abraham, "Hybrid intelligent systems: evolving intelligence in hierarchical layers," in Do Smart Adaptive Systems Exist? Springer, 2005, pp. 159-179.

[25] Y. Yousif, K. Daws, and B. Kazem, "Prediction of friction stir welding characteristic using neural network," Jordan Journal of Mechanical and Industrial Engineering, vol. 2, no. 3, 2008.

[26] G. Dreyfus, Neural networks: methodology and applications. Springer Science \& Business Media, 2005.

[27] R. C. Eberhart, J. Kennedy et al., "A new optimizer using particle swarm theory," in Proceedings of the sixth international symposium on micro machine and human science, vol. 1. New York, NY, 1995, pp. 39-43.

[28] J. Kennedy, J. F. Kennedy, R. C. Eberhart, and Y. Shi, Swarm intelligence. Morgan Kaufmann, 2001.

[29] R. Poli, "Analysis of the publications on the applications of particle swarm optimisation," Journal of Artificial Evolution and Applications, vol. 2008, p. 3, 2008.

[30] J. Kennedy, "Particle swarm optimization," in Encyclopedia of machine learning. Springer, 2011, pp. 760-766.

\section{APPENDIX}

Abbreviations, the operating conditions and technical aspects of the distillation column are detailed in following table.

\begin{tabular}{|c|l|c|c|}
\hline Symbol & Description & Value & Unit \\
\hline$N$ & Number of trays & 20 & - \\
\hline$N_{F}$ & Feed stage location & 11 & - \\
\hline$F$ & Typical inlet flow rate to the column & 1 & $\mathrm{kmol} / \mathrm{min}$ \\
\hline$D$ & Typical distillate flow rate & 0.5 & $\mathrm{kmol} / \mathrm{min}$ \\
\hline$B$ & Typical bottoms flow rate & 0.5 & $\mathrm{kmol} / \mathrm{min}$ \\
\hline$z F$ & $\begin{array}{l}\text { Light component in the feed (mole frac- } \\
\text { tion) }\end{array}$ & 0.5 & - \\
\hline$q_{F}$ & Mole fraction of the liquid in the feed & 1 & - \\
\hline$L$ & Typical reflux flow rate & 1.28 & $\mathrm{kmol} / \mathrm{min}$ \\
\hline$V$ & Typical boil-up flow rate & 1.78 & $\mathrm{kmol} / \mathrm{min}$ \\
\hline$\alpha$ & Relative volatility & 2 & - \\
\hline$x D$ & Distillate composition (mole fraction) & 0.98 & - \\
\hline$x B$ & Bottoms composition (mole fraction) & 0.02 & - \\
\hline$i$ & Stage number during distillation & - & - \\
\hline$x$ & $\begin{array}{l}\text { Mole fraction of light component in } \\
\text { liquid }\end{array}$ & - & - \\
\hline$y$ & $\begin{array}{l}\text { Mole fraction of light component in } \\
\text { vapour }\end{array}$ & - & - \\
\hline$M$ & Tray hold-up liquid & 0.5 & $\mathrm{kmol}$ \\
\hline$M D$ & Condenser hold-up liquid & 0.5 & $\mathrm{kmol}$ \\
\hline$M B$ & Reboiler hold-up liquid & 0.5 & $\mathrm{kmol}$ \\
\hline
\end{tabular}

